would be possible to get five times as much light for a sovereign as could be done now. At present electric lighting would succeed commercially where other considerations than cost had weight. Improvements in the lamps were certain, and there was a probability that these improvements might go so far as to reduce the cost to one-fifth of what it now was. He left the meeting to judge whether or not it was probable, nay, almost certain, that lighting by electricity was to be the lighting of the future.

\section{HARDENING AND TEMPERING STEEL}

$\mathrm{O}^{\mathrm{NE}}$ of a series of lectures to the Liverymen and Apprentices of the Company of Cutlers of London was delivered on Thursday last by Prof. W. Chandler Roverts, F.R.S., "On some Theoretical Considerations connected with Hardening and Tempering Steel."

The Master of the Company, Mr. J. Thorne, presided, and the Lecturer observed tbat the 'phenomena with which they had to deal, although admittedly as interesting and remarkable as any in the whole range of metallurgy, are but little understood.

If the fact that steel can be hardened had not been known, the whole course of our industrial and even political history would probably have been widely different, and the dagger, which occupies so prominent a place in the armorial bearings of the City of London, would have represented a survival of implements made, not of steel, but of copper hardened with tin.

It has long been known that there are extraordinary differences between the properties of wrought iron, steel, and cast iron, but our knowledge that these differences depend upon the presence or absence of carbon is only a century old, for it was not until the year $\mathbf{1 7 8} \mathrm{I}$ that Bergman, Professor in the University of Upsala, showed that wro ght iron, steel, and cast iron, when dissolved in certain acids, leave amounts of a graphitic residue, varying from $\frac{1}{10}$ to $2 \frac{1}{2}$ per cent., which are essential to the constitution of these three varieties of metal. Bergman's work led many early experimenters, notably Clouet in 1796 , to attempt to establish the importance of the part played by carbon, and Clouet converted pure iron into steel by contact at a high temperature with the diamond, which was the purest form of carbon he could command. Prof. Roberts said that this experiment had been repeated by many other observers with varying success, as in all the earlier work the furnace gases, which had not been excluded, might have converted the iron into steel without the intervention of the diamond. It remained for a distinguished Master of the Cutlers' Company, Mr. W. H. Pepys, to repeat Clouet's fundamental experiment under conditions which rendered the results unequivocal, by en ploying electricity as a source of heat. This experiment, which had been communicated to the Royal Society in 1815 , was performed in the way Pepys had indicated.

It was then shown that in soft, tempered, and hardened steel respectively the carbon has a distinct "mode of existence," as is indicated by the widely different action of solvents on the metal in these three states.

The evidence as to whether carbon in steel is combined in the chemical sense, or is merely dissolved, was then considered at some length, special reference being made to the results obtained by various experimenters, from Berzelius and Karsten to Sir Frederick Abel of the War Department.

Prof. Roberts stated that the researches of Troost and Hautefeuille afforded strong evidence that in "white cast-iron" and steel the carbon is merely dissolved, a view which he adopted, as he did not consider it to be at all in opposition to the facts recently established by Sir Frederick Abel, who had shown that the carbon may be left by the slow action of solvents on soft steel as a carbide of iron.

The various physical, as distinguished from the chemical theories that had been propounded from the time of Réaumur, (I722) to that of Akerman (1879), to account for the "intimacy of the relation" of carbon and iron in hard as compared with soft steel, were then described at some length, and the remarkable experiments of Réaumur, who cooled steel slowly in a Torricellian vacuum in order to show that the absorption of gas did not take place during cocling, was illustrated.

In recent years much importance has been attached to the physical evidence as to the peculiar constitution of steel, and it has been shown that there is a remarkable relation between the amount of carbon contained in different varieties of steel and their elestrical resistance. Some of the very interesting experi- ments of Prof. Hughes on this point were then exhibited and described, and Prof. Roberts concluded by saying that the value of the early work by Bergman and Réaumur had rather been lost sight of in recent discussions, Bergman's work being specially remarkable, as he attempted, by thermometric measurement, to determine the heat equivalent of the phlogiston he believed iron and steel to contain.

The importance of the degree of carburisation of steel from the point of view of its technical application was illustrated by reference to a series of curves, and it was incidentally mentioned that, in the case of the variety of steel used for the manufacture of coinage-dies, the presence of $\frac{1}{10}$ per cent. of carbon more or less than a certain standard quantity makes all the difference in the quality of the metal.

\section{UNIVERSITY AND EDUCATIONAL INTELLIGENCE}

OXFORD. - The new Board of the Faculty of Natural Science has issued its first list of lectures this term. The lectures are divided under the following heads :-Physics, Chemistry, Animal Morphology, Geology, and Botany. No lectures are scheduled this term under Mineralogy or Physiology.

In Physics Prof. Clifton lectures on "Instruments and Methods of Measurement employed in the Study of Optics." These lectures are given in the Clarendon laboratory, where practical instruction in Physics is given by the Professor, assisted by Messrs. Stocker and Heaton. At Christ Church $\mathrm{Mr}$. Baynes lectures on Electrokinematics and Electrodynamics, and gives practical instruction on Electric and Magnetic Measurements. At Balliol Mr. Dixon gives a course of experimenta lectures on Elementary Heat and Light.

In Chemistry Dr. Odling lectures at the Museum on the Composition of Air and Water; Mr. Fisher lectures on Inorganic Chemistry; and Dr. IVatts on the Cyanogen Series. At Christ Church Mr. Harcourt has a class for Quantitative Analysis, and Mr. Dixon a class for Ga: Analysis.

In Animal Morphology Prof. Moseley lectures on Comparative Anatomy, and gives practical instruction to his class after each lecture; Mr. Hickson lectures on the Development of the Chick, Mr. Hatchett Jackson on Mammalian Osteology and the Principles of Embryology, Mr. Poulton on the Di-trisution of Animals, and Mr. Lewis Morgan on the Vertebrate Exoskeleton and on Human Osteology.

In Botany Mr. Chapman gives practical instruction on Vege. table Morphology at the Botanic Gardens.

In Geology Prof. Prestwich will give a series of lectures on Friday afternoons on the strata and fossils to be visited on his Saturday excursions.

On June 19 an examination will be held in common by Mag. dalen, Merton, and Corpus Christi Colleges for electing a Scholar in Physical Science at each College. At Merton and Corpus the chief subjects will be Chemistry and Physics.

Iesus College offers a Welsh Scholarship in Natural sicience. The examination will be held on June $\mathbf{1} 4$.

Examinations for the degree of Bachelor of Medicine (both First and Second) will be held this term. Candidates are to send in their names before May $\mathrm{x}$.

CAmbridge.-Prof. Huxley's Rede Lecture at Cambridge University will be given on June 12, at 3 p.m., in the Senate House. The subject is not yet announced.

Dr. Michael Foster leaves the Lectures on Elementary Biology for this term in the hands of Dr. Vines and Mr. Sedgwick, and will hold Catechetical Classes in Physiology for the Natural Sciences Tripos.

Dr. F. Darwin will give six Demonstrations on the Physiology of Plants (Growth, Movement, \&c.) at the Physiological Labora. tory on Saturdays at noon, beginning April 2 I.

Prof. Liveing will lecture on the Chemistry of the Heavenly Bodies, beginning May I.

London.-Mr. A. H. Keane has been uppointed to the Hindustani Lectureship at University College.

THE Winter Session at the College of Agriculture, Downton, near Salisbury, ended on Monday, when the certificates and prizes were presented to the successful students by Archdeacon Sanctuary. The certificate of membership, obtainable on examination after completion of the two years' course of study, was granted to Mr. Arthur Herbert Kerr, Crookham, Farnham, 
and to Mr. Henry Blair Mayne, Brantridye Park, Balcombe. The scholarship, open to first-year students, was awarded to Mr. Robert Alan Benson, Clifton.

\section{SOCIETIES AND ACADEMIES LONDON}

Mathematical Society, April 12.-Prof. Henrici, F.R.S., president, in the chair. - The Chairman announced that Prof. Rowe, of University College, London, had been elected a Member of the Council in the room of the late Prof. Henry Smith, F.R.S. - The following communications were made:-Equations of the loci of the intersections of three tangent lines and of three tangent planes to any quadric $u=0$, Prof. Wolstenholme. - Investigation of the character of the equilibrium of an incompressible heavy fluid of variable density, Lord Rayleigh, F.R.S. - On the normal integrals connected with Abel's theorem, Prof. Forsyth.-Spherical functions, Part I, Rev. M. M. U. Wilkinson.-Calculation of the equation which determines the anharmonic ratios of the roots of a quintic, Prof. M. J. M. Hill. -On simultaneous differential equations, with special reference to (I) the roots of the fundamertal determinant, (2) the method of multipliers, Mr. E. J. Routh, F.R.S.

Chemical Society, April 5--Dr. W. H. Perkin, president, in the chair. - It was announced that a ballot for the election of Fellows would take place at the next meeting of the Sociaty (April 19).- The following papers were read:-On the estimation of hydrogen sulphide and carbonic anhydride in coal-gas, by L. T. Wright. The coal-gas, dried and freed from ammonia, is passed through two weighed U-tubes, the first containing precipitated cupric phosphate dried at $100^{\circ}$ and calcium chloride, the second, soda lime, slightly moist, and calcium chloride. Three cubic feet of clean coal-gas are first passed through the U. tubes to "saturate" the reagents. The increase of weight of the first U-tube, after the passage of the crude coal-gas, then gives the hydrogen sulphide, and the increase in weight of the second the carbonic anhydride.-Some compounds of antimony and bismuth containing two halogen=, by R. W. Atkinson.-On the theory of a molecular combination, when antimonious chloride is mixed with potassium bromide and antimonious bromide with potassium chloride, two distinct compounds should be produced. The author finds that but one is formed, the two compounds heing identical in composition as well as in colour, crystalline form, and other physical characters. This body has the formula $\mathrm{Sb}_{2} \mathrm{Cl}_{6} \mathrm{Br}_{6} \mathrm{~K}_{6}+{ }_{3} \mathrm{H}_{2} \mathrm{O}$. An attempt to form the corresponding bismuth compound was not successful.-Contribution to the chemistry of the cerite metals, by B. Brauner. The author has determined the atomic weight of didymium with the greatest care, and fixes it at $145^{\circ} 4$; the higher numbers previously obtained were due to the presence of a metal having a higher atomic weight; this metal is proved by the author to be samarium, the atomic weight of which he calculates to be 150 . The author also proves that the principal gadolinite earthsyttria, terbia, erbia, \&c.- are present in cerite, but not in large quantities.

Institution of Civil Engineers, April 3.-Mr. Brunlees, president, in the chair.- The paper read was "On the SummitLevel Tunnel of the Bettws and Festiniog Railway," by Mr. William Smith, M.Inst.C.E.

A pril 10.-Mr. Brunlees, president, in the chair.-The paper read was on "The Introduction of Irrigation into New Countries, as illustrated in North-Eastern Colorado," by Mr.. P. O'Meara, M.Inst. C.E.

\section{EDINBURGH}

Royal Society, April 2.-Mr. John Murray in the chair.Dr. Gibson, in a communication on some laboratory arrangements, described and exhibited a modification of Bunsen's method of filtration. The modification consisted essentially in placing the vessel which received the filtrate inside a bell-jar, which was connected with the exbansting apparatus and perforated above so as to admit the funnel through which the liquid filtered. By a suitable three-way stopcock arrangement the adjusting of the internal partial vacuum was kept quite under the control of the experimenter. A contrivance for the more convenient use and better preservation of sulphuretted hydrogen water was also described and shown.--Prof. Tait, in a short note on the thermoelectric position of pure cobalt, described recent experiments which fally bore out results formerly obtained with other specimens. The cobalt line runs nearly parallel to the iron line, but far down on the diagram below palladium and nickel. Prof. Tait also indicated the solution of certain problems of heat conduction in heterogeneous bodies as affected by the Peltier and Thomson effects. - Prof. George Forbes read a paper on transmission of power by alternate currents, in which he pointed out the value of alternate current machines as electromotors, especially in cases in which perfect isochronisin was of importance. - Prof. Herdman, in a paper on the so-called hypophysis in the Tunicata, described the structure of the netral (hypophysal) gland and the dorsal tubercle in various Ascidians, and suggested that possibly the connection of the neural gland (and also of the vertebrate hypophysis cerebri) with the pharynx might be a secondary modification caused by one or more of a series of primitive lateral excretory ducts, opening either upon the exterior of the body or into the peribranchial cavity, having come to open into a lost sense organ, in the Stomodæum represented by the dorsal tubercle. These lateral ducts are found in Ascidia mammillata, in some cases existing along $\mathrm{u}$ ith a median duct opening into the pharynx at the dorsal tubercle, and in other cases without this connection with the supposed sense-oryan.Prof. Tait presented a paper on the quaternion expression for the displacements of a rigid system, by Dr. G. Plarr.

Mathematical Society, April 13.-Mr. A. J. G. Barclay, M.A., in the chair.-Mr. J. S. Mackay, president, read a paper on the triangle and its six-scribed circles, adding historical notes on the discovery of the various properties enumerated. The name medioscribed circle (il circolo medioscritto) u as suggested for use instead of nine-point circle, as had been proposed twenty years ago by G. B. Marsano, "Considerazioni sul Triangolo Rettilineo," Genova, I863, p. I I.

\section{BERLIN}

Physiological Society, March 9.-Prof. Du Bois Reymond in the chair.-Dr. Wernicke gave a short sketch of the illness of a patient who fell sick, exhibiting all the symptoms of a cerebral tumour except epsleptic attacks, and who manifested a disturbance of speech that was characterised by Dr. Wernicle as a "sensorial aphasia," and by others as "word-deafness." A sensorial aphasia consists, according to Dr. Wernicke, in the fact that the patients, though in possession of a large vocabulary, no longer understand the meaning of words, that they use these confusedly, and so that their speech is quite muddled; moreover they do not understand what one says to them at all, so that it is impossible to arrive at an understanding with them. The patient in question soon succumbed to an intercurrent disease, and it was possible to make a thorough dissection of the brain, which exhibited a bilateral affection of the cerebral cortex at the first temporal convolution. An accurate dissection of the ears showed that the deafness that had been observed during life was not brought about by any disease of the sound-conducting apparatus, but that it was rather to be regarded as a central deafness conditioned by the disease of the cortex of the first sphenosemporal convolution in which, as Dr. Wernicke made probable to long as ten years ago, the terminal expansion of the acoustic nerve has its seat. Now the local disease of the brain-cortex and the consequent observed disturbances in hearing and speech correspond to the manifestations of "soul-deafness" that were experimentally produced by Dr. Munk in animals by extirpation of the auditory sphere (Hörsphäre), and consequently establish the results of experiments on animals as true for man also. The tolal deafness of the patient had only set in at a later period towards the end of the disease, when the affection of the brain had passed from the cortex into the deeper structures and had destroyed the acoustic fibres. The physiological import of the above case consists in the clearly proved limitation of the disease to the first temporo-sphenoidal convolution in a case where the clinica! phenomena corresponded accurately to those of "soul-deafness." -Dr. J. Munk had found in previous experiments that the func. tion of neutral fats in nutrition can just as well be performed by the fatty acids. Animals manifested absolntely no disturbance of nutrition when supplied with fatty acids instead of fats; the fatty acids were made into an emulsion, and absorbed by the villi in precisely the same fashion as the fats, and afterwards the chyle-vessels were found just as densely filled with a milky fluid as after a meal of fat. The examination of the chyle had, however, shown that the fatty acids that were supplied were no longer to be found, but only neutral fats, and hence Dr. Munk had assumed that a synthesis of neutral fats took place as the fatty acids passed out of the intestinal villi into the chyle, and that the glycerine was sup. plied by the animal body, probably by the breaking down of albu- 